\title{
Study of stand-alone building heating system operating with renewable energy sources under moderate continental climate conditions
}

\author{
Ivan Sokolov ${ }^{1, *}$, Artem Ryzhenkov $^{1}$, Elizaveta Tyabut ${ }^{1}$ \\ ${ }^{1}$ National research university «MPEI», Moscow, Russia
}

\begin{abstract}
The climatic conditions in Moscow limit to a certain extent the utilization of renewable energy sources for heat supply. Long heating period, relatively low average daily sunshine hours during heating period, and low outside temperatures act as barriers to realising the full potential of renewable energy sources. The paper presents an evaluation of feasibility and effectiveness of using various renewable energy sources in the heat supply system of Block 23 of the National research university «MPEI». The system arrangement for heat supply of the building with renewable energy sources is described. Experimental data have been obtained on the basis of this system. The calculated time dependences of building heat consumption and heat pump system (HPS) outputs are given. In addition, for the air-source heat pump system, the dependence on the outdoor temperature is given. Values of HPS efficiency indices are also presented. A comparative analysis of the efficiency of air-source HPS and liquid-to-liquid HPS with a geothermal circuit in winter conditions is carried out.
\end{abstract}

\section{Introduction}

Nowadays, increasing the scope of renewable energy applications is a priority for many developed countries, including the Russian Federation [1], [2]. The use of renewable energy sources for heating and cooling of buildings, which accounts for about $46 \%$ [3] of global heat generation, will significantly reduce the consumption of fossil fuels. This means reducing atmospheric emissions, reducing the energy intensity of energy industry, and supplying remote locations that are difficult to reach with district heating.

For heat supply in stand-alone buildings, the use of HPS seems promising. Using low-temperature heat that is freely available in the environment, heat pumps used in heating supply provide transformation coefficients within the order of 2-5, depending on the type of lowtemperature heat source and its temperature, and depending on the desired thermal potential of the heat transfer agent.

According to the International Energy Agency, the share of HPS in heating residential houses has increased from $2.9 \%$ in 2010 to $5 \%$ in 2019 , with a projected increase to $15 \%$ by 2025 (see Fig. 1) [4].

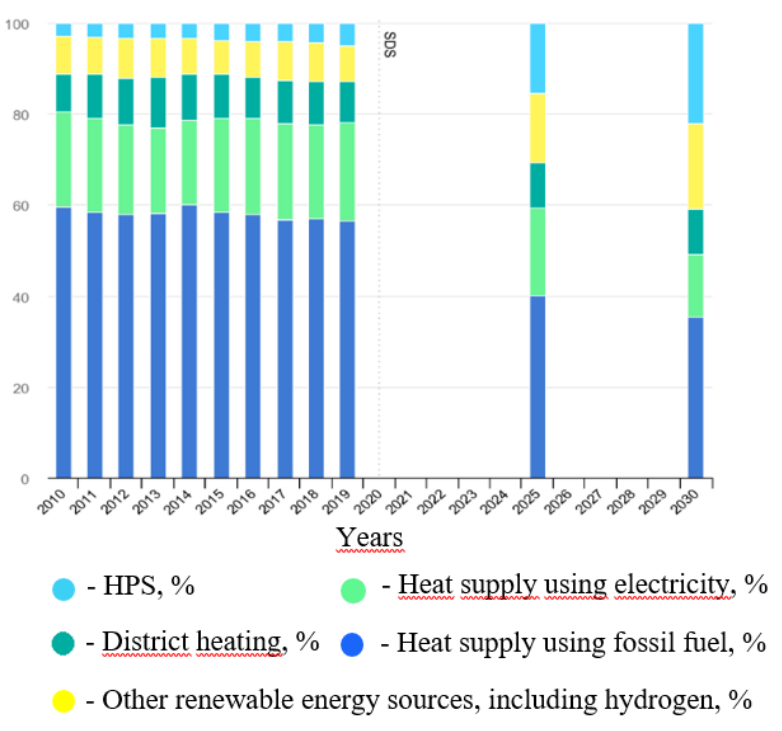

Fig. 1. Share of different types of sources in residential heat supply systems [4]

The key markets for HPS heating residential applications are North America, Europe and North Asia [4], while China has experienced the most significant growth in the use of heat pump systems for heating [5]. Fig. 2 shows the cumulative increase in the area of administrative and residential buildings heated by heat pumps utilizing the ground as a low-temperature heat source.

\footnotetext{
* Corresponding author: sokolviv@inbox.ru
} 


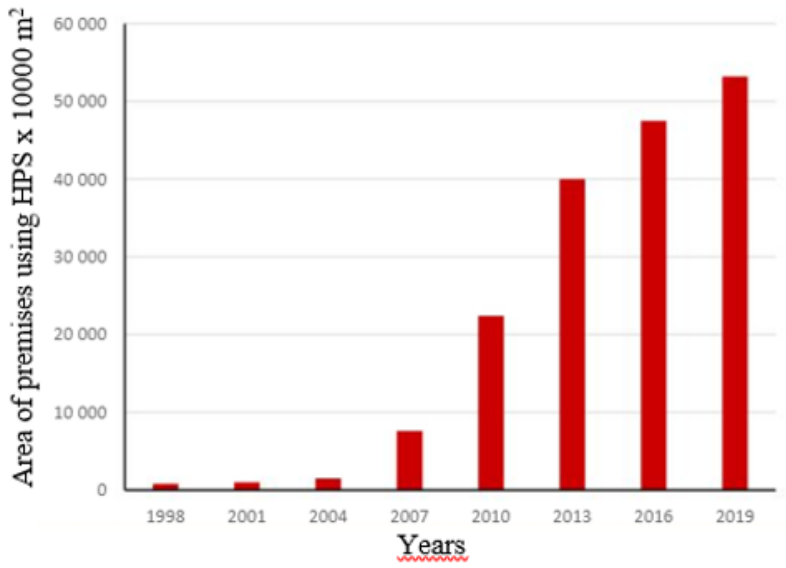

Fig. 2. Increase in area of premises in China where HPS are used for heating and cooling [5]

In recent years, a large number of studies on heat supply using HPS have been made:

Heat consumption of administration building in a hard-to-reach area of Tibet was fully supplied by means of air heat pumps in combination with solar collectors [6], [7].

A system consisting of a HPS with geothermal circuit ( $50 \mathrm{~m}$ borehole with double U-tube placed in it) and 6.5 $\mathrm{m}^{2}$ flat solar collectors has been studied in Plovdiv, Bulgaria [8].

In Harbin, China, a hybrid heat supply system consisting of a ground source HPS and solar collectors was studied [9]. The average system transformation coefficient of 6.55 was achieved.

The research paper [10] investigated the various modes of operation of air HPS in the heat supply system of northwest regions of China.

A special case is Sweden, where HPS with an aggregate capacity of up to $1,527 \mathrm{MW}$ have been used to provide district heating [11]. However, in Sweden the main sources of low-temperature heat were: sewage water, water from seas and lakes, and rejected excess heat from industrial plants [11]. According to [12], HPS using ground heat as a low-temperature heat source can only compete with district heating in suburban areas due to its high specific land consumption. Currently in Sweden, HPS are gradually superseded by biofuel plants, partly due to high electricity prices.

Research work [13] has simulated the operation of air HPS as a heating source for area of North China in combination with the traditional Chinese Kang heating system, which is in effect a thermal energy storage system. Based on the simulation results, it was possible to maintain the room temperature at a constant, comfortable level.

The study [14] has compared the efficiency of air HPS and HPS with geothermal circuit. Despite the lower initial investment, the air HPS was found to be less efficient with a time in service of more than 12 years. In addition, the effect of using an economizer in HPS cycle on their efficiency was evaluated. The use of economizer increased the transformation coefficients for ground source and air HPS units by $9 \%$ and $7.5 \%$ respectively, and also increased the exergy efficiency by $6.8 \%$ and $7.4 \%$ respectively.

A feasibility study on air HPS for heating in Northern China conducted in paper [15] demonstrated its energy consumption to be lower than any other heating method except cogeneration coal-fired thermal power plants, which, however, have a negative impact on the environment. However, despite its low energy consumption, the air HPS requires modifications to the heating system to operate at temperatures below $-5^{\circ} \mathrm{C}$. This is caused by the need for too high compressor pressure ratios, as it is necessary to heat the heat transfer agent to $75^{\circ} \mathrm{C}$ and above in order to run the heating system on standard radiators. This means an implementation of low-temperature heating systems, additional building insulation and use of thermal energy storage systems are needed.

Based on the above studies of recent years, it can be concluded that heat supply with renewable energy sources, including HPS, is feasible if certain conditions are met.

One of the main advantages of heat supply systems based on renewable energy sources and in particular heat pumps is their ability to supply hard-to-reach and remote locations where there is no district heating and the supply of fuel for hydrocarbon-based heating systems is difficult. The implementation of such systems will reduce the energy intensity of heating supply energy industry and reduce the harmful atmospheric emissions from combustion of fossil fuels.

The major barriers to the widespread use of HPS heating systems are the high initial investment costs and the high specific land consumption when it comes to ground source heat pumps. Also, there is a need to use traditional heating techniques for peak periods to cover the heat consumption when used in the cold climate conditions typical of the Russian Federation. In addition, the use of low-temperature heating systems to achieve higher transformation coefficients as well as the use of energy storage systems to achieve savings by shifting electricity consumption peaks to the night hours are recommended. This would give the highest efficiency of the HPS-based heat supply system.

\section{Arrangement of heat supply system}

Block 23 of the National research university «MPEI» (henceforth "the building") is a three-storey building with a basement. It is a category 2 public building - a space for people engaged in brainwork.

The area is $455 \mathrm{~m}^{2}$ and the total volume of building is $1375 \mathrm{~m}^{3}$

The following heat sources have been selected for the building heating system:

liquid-liquid HPS with a capacity of up to $13 \mathrm{~kW}$ with a ground-source circuit comprising four double U-tubes placed in boreholes;

air HPS with a capacity of up to $8.8 \mathrm{~kW}$ at supply water temperature of $55^{\circ} \mathrm{C}$;

flat solar collectors with a total area of $10 \mathrm{~m}^{2}$. 
System arrangement for heat supply of the Block 23 is shown in Fig. 3.

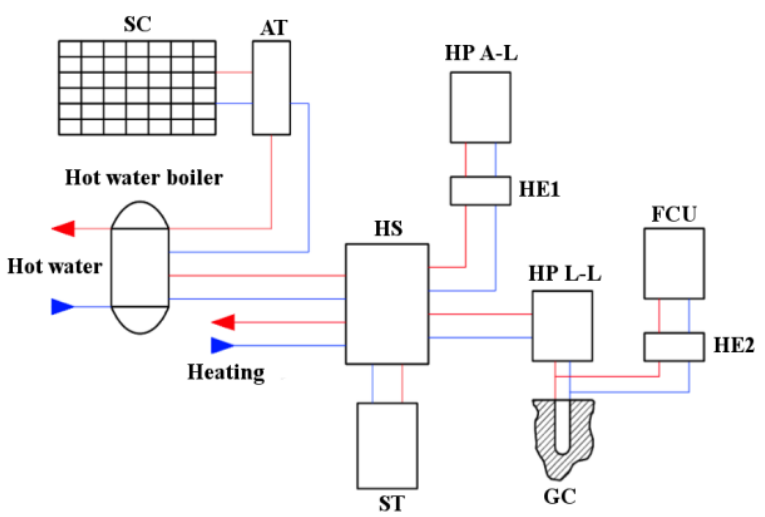

SC - solar collectors, AT - accumulation tank, HP A-L air-liquid HPS, HP L-L - liquid-liquid HPS, HE1, HE2 heat exchangers, HS - hydraulic separator, FCU - fan coil units, ST - storage tanks, GC - geothermal circuit.

Fig. 3. Schematic diagram of heat supply system for Block 23

The heat sources are integrated into a single circuit by means of a hydraulic separator (HS), which is a 300 litre tank that enables distribution of the heat transfer agent to supply the hot water, heating and air-conditioning consumption. In addition to HS, the system is also equipped with three storage tanks, each with a capacity of 400 litres.

Each pipe connecting HS and heat sources, as well as the pipes leading directly to the heating and hot water supply network, are fitted with resistance temperature detectors and ultrasonic flow meters to monitor the heat transfer agent parameters and evaluate the system's efficiency.

The system is controlled by a programmable logic controller.

\section{Research methods}

The key efficiency indices of HPS were chosen: : transformation coefficient, which can be determined by formula (1), where $G_{c}$ is the heat transfer agent flow through the evaporator, $\mathrm{kg} / \mathrm{s} ; \mathrm{C}_{\mathrm{p}}$ is heat capacity of heat transfer agent, $\mathrm{J} / \mathrm{kg}^{* \mathrm{o}} \mathrm{C} ; \Delta \mathrm{t}_{\mathrm{c}}$ is temperature difference of heat transfer agent at condenser, ${ }^{\circ} \mathrm{C} ; \mathrm{N}$ is the power consumed by HPS, W:

$$
C O P=\frac{G_{\mathrm{c}} C_{p} \Delta t_{\mathrm{c}}}{N}
$$

and HPS efficiency, determined by formula (2), where $\tau_{\mathrm{q}}-$ exergy factor of HPS:

$$
\eta=\frac{G_{\mathrm{c}} C_{p} \Delta t_{\mathrm{c}} \tau_{q}}{N}
$$

Calculation of the hourly heating consumption of the building was carried out by aggregate-based indices according to formula (3), where $\alpha$ is corrective factor taking into account the difference between the estimated outdoor air temperature for heating design and $\mathrm{t}_{0}=-30^{\circ} \mathrm{C}$; $\mathrm{V}$ is the building volume by outward measurement, $\mathrm{m}^{3} ; \mathrm{q}_{0}$ $s$ the building heating characteristic at $\mathrm{t}_{0}=-30^{\circ} \mathrm{C}$; $\mathrm{t}_{\mathrm{j}}$ is the estimated outdoor air temperature, ${ }^{\circ} \mathrm{C} ; \mathrm{K}_{\text {i.e. }}$ is the estimated infiltration rate:

$$
Q_{0}=\alpha V q_{0}\left(t_{j}-t_{0}\right)\left(1+K_{i . e .}\right)
$$

The estimated infiltration rate is determined by formula (4), where $\mathrm{g}$ is the acceleration due to gravity, $\mathrm{m} / \mathrm{s}^{2}$; L is the unsupported height of the building, $\mathrm{m} ; \mathrm{w}_{0}$ is the estimated wind speed for this location during heating period, $\mathrm{m} / \mathrm{s}$ :

$$
K_{\text {i.e. }}=10^{-2} \sqrt{\left[2 g L\left(1-\frac{273,15+t_{0}}{273,15+t_{j}}\right)+w_{0}^{2}\right]}
$$

The permissible error of the values measured directly:

- for temperatures is $\pm 1,5 \%$;

- for flow rates is $\pm 1 \%$;

- for power consumption is $\pm 2 \%$.

The permissible error of the values determined by calculation:

- for transformation coefficient is $\pm 4,5 \%$;

- for HPS efficiency is $\pm 4,5 \%$.

\section{Results and discussion}

To estimate the duration of possible period for covering heat demand of the building, heat consumption was calculated on aggregate basis. The dependence of hourly heat consumption on outdoor temperature is shown in Fig. 4 .

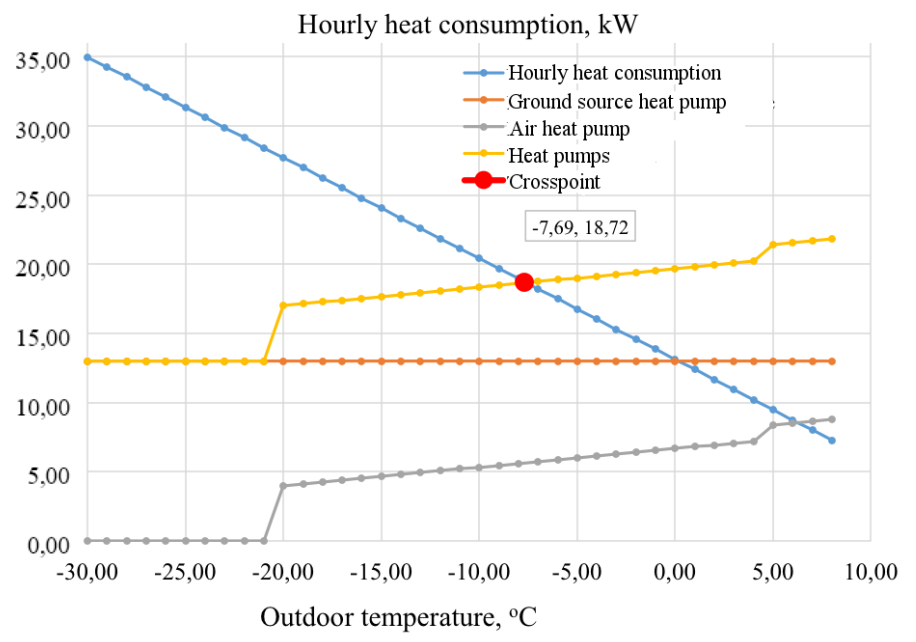

Fig. 4. Dependence of hourly building heat consumption on outdoor air temperature

The outdoor temperature at which the transition to heat supply solely by renewable energy sources becomes possible is $-7,69^{\circ} \mathrm{C}$, with consumption of $\sim 18,72 \mathrm{~kW}$.

Heat energy generation by solar collectors was not taken into account when finding the transition point, as the average daily number of sunny hours in the city of Moscow is $\sim 1$ during the winter period with particularly low temperatures. In addition, the precipitation covering 
the receiving surface of solar collectors falls about 5 days per month, hence their use for heat supply is not feasible.

In order to determine the period during which an additional heat source is required, a Rossander graph has been drawn for the building. (Fig. 5.)

Heat consumption, $\mathrm{kW}$

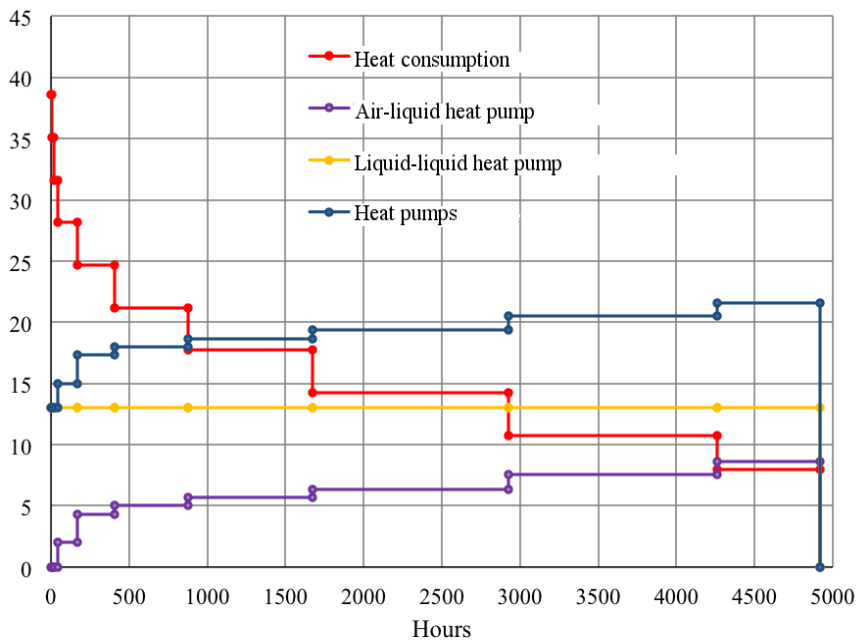

Fig. 5. Rossander graph for Block 23

According to the calculation, the use of renewable energy sources allows to fully cover the needs of the building in heat energy during 4046 hours, or $82.2 \%$ of the duration of the heating period. So to provide peak heat consumption for a period of 874 hours, representing $17.7 \%$ of the total assumed heating period for the building, an electric boiler is integrated into the heat supply arrangement in addition to the renewable heat sources.

The Rossander graph also demonstrates the need to operate the ground source HPS during 4,260 hours, which is $86.5 \%$ of the total heating period and $48.6 \%$ of the total heating period and inter-heating period. For the remaining time, the heating consumption as well as the hot water consumption can be fully supplied by air HPS unit and solar collectors.

The graph in Fig. 6 shows that the liquid-to-liquid HPS demonstrates a transformation coefficient up to 2.5 at the evaporator outlet temperature $\sim 55^{\circ} \mathrm{C}$.

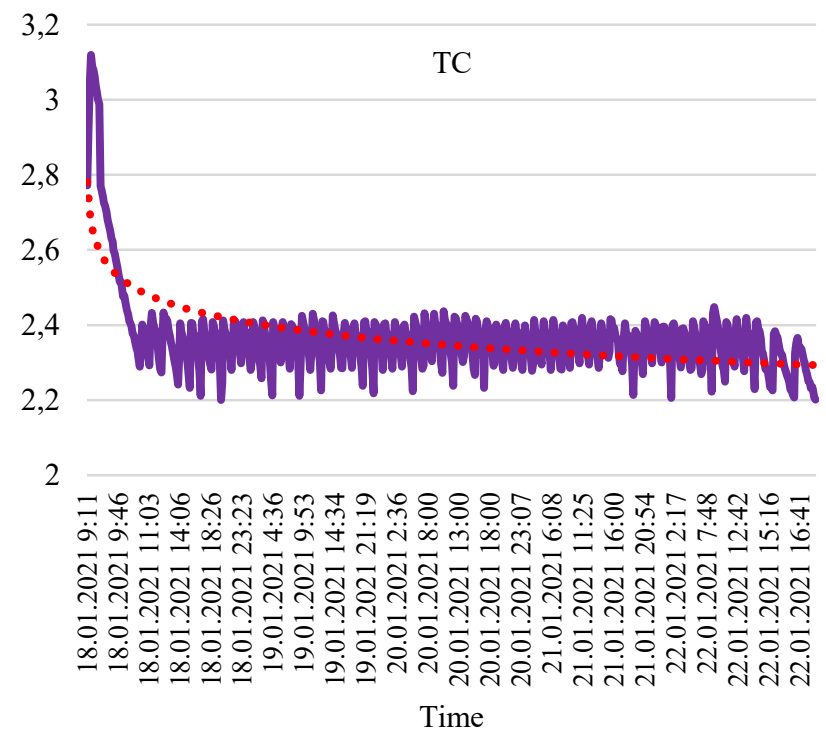

Fig. 6. Variation of transformation coefficient during liquid-to-liquid HPS operation by operating time

It should be noted that during the initial period of operation, if the temperature difference between the heat transfer agent from the geothermal circuit entering the evaporator and the heat transfer agent extracting heat energy in the condenser is $<40^{\circ} \mathrm{C}$, then the heat pump's transformation coefficient reaches 3.1. However, this value is only typical for the first two HPS activation periods until it has reached the nominal operating mode, in which the transformation coefficient is $\sim 2.4$.

During more than 110 hours of continuous HPS operation, there was an average soil temperature decrease of $0.48^{\circ} \mathrm{C}$ over the total depth of the borehole. Under the conditions of this experiment, the decrease in soil temperature had no significant effect on the HPS operation. However, in future years of operation, the capacity of HPS with geothermal circuit will steadily decrease due to ground cooldown, as the short interheating period will not allow the temperature potential of the geothermal circuit to be fully restored.

As for the efficiency, its average value during HPS operation after reaching the nominal mode is 0.31 . During the heating period of heat transfer agent in hydraulic separator, when the transformation coefficient is close to 3 , the efficiency is $\sim 0.42$.

The air HPS exhibits a transformation ratio close to 1 for 404 hours, or $\sim 8.2 \%$ of the duration of the heating period. This time can be reduced by lowering the required temperature at the outlet of HPS evaporator.

Fig. 7 shows the time dependence of air HPS transformation coefficient at outdoor temperature of $\sim$ $6^{\circ} \mathrm{C}$. Similarly to liquid HPS, during the initial period of operation, if the temperature in the heated vessel has not yet reached the nominal value of $55^{\circ} \mathrm{C}$, the transformation coefficient of air HPS reaches a value of 2.0 at temperature difference between outdoor air and heat transfer agent at condenser outlet of $\sim 40^{\circ} \mathrm{C}$. The transformation coefficient decreases gradually, almost reaching a value of 1 at temperature difference between outdoor air and heat transfer agent at condenser outlet of $>50^{\circ} \mathrm{C}$. The decrease is due to the inability to provide high enough pressure ratio by compressor to achieve the required condenser outlet temperature.

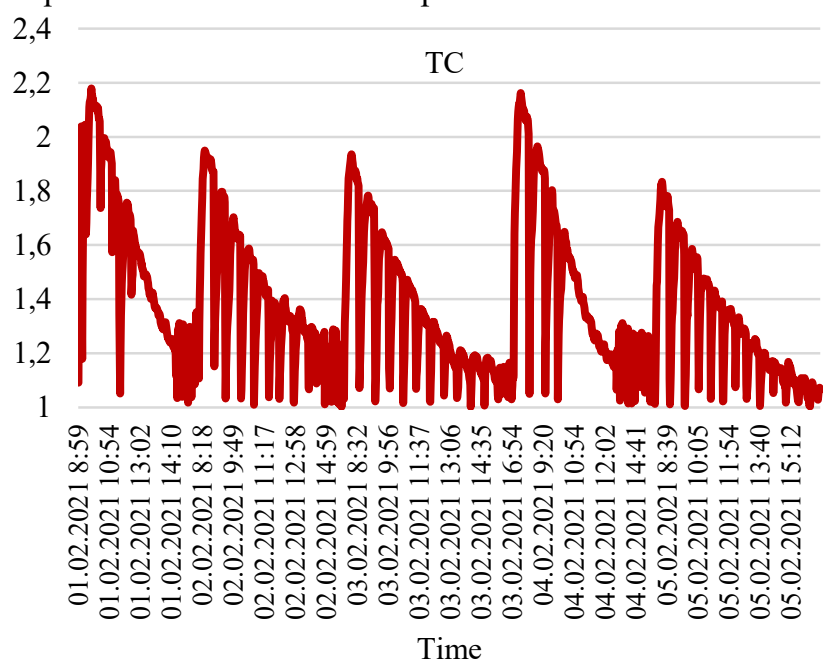


Fig. 7. Variation of transformation coefficient during air HPS operation by operating time

In this case, the efficiency of air HPS in the initial period of operation when the heat transfer agent is heated in hydraulic separator to a temperature of $55^{\circ} \mathrm{C}$ is over 0.27 . The average efficiency during operation of air HPS is 0.23 .

Based solely on transformation coefficient values, the HPS with geothermal circuit is significantly superior to the air HPS both in the initial period of heat transfer agent heating to the target temperature and in the nominal operating mode.

However, it should be noted that during the lowest efficiency period of air HPS, it must be combined with the ground source HPS in order to supply the heating consumption.

As the heat consumption decreases due to an increase in the outdoor temperature, this in turn leads to an increase in transformation coefficient of air HPS.

Therefore, to slow down the capacity reduction of a ground source HPS, which has a decreasing transformation coefficient during operation due to decreasing ground thermal potential, it is reasonable to use an air HPS instead of a ground source HPS as long as possible at outdoor temperatures allowing for an average transformation coefficient $>2$.

Solar collectors are able to supply the building's hot water demand during the inter-heating period. Efficiency decreases during the marginal months of the heating period. From December to February the collectors are inefficient due to low average daily sunlight hours, low air temperatures and frequent covering of the receiving surfaces with snow. The temperature variation in the accumulation tank of solar collectors during the winter period is shown in Fig. 8.

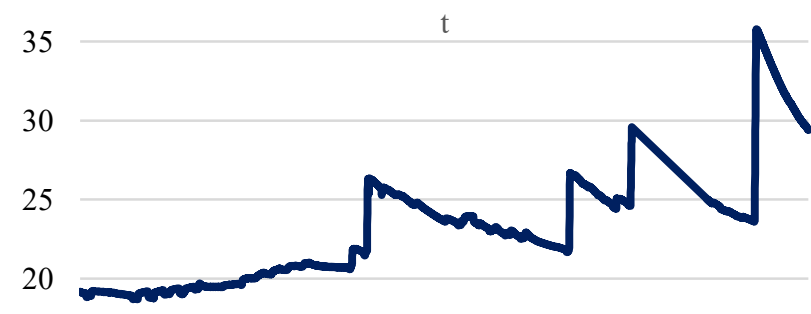

15

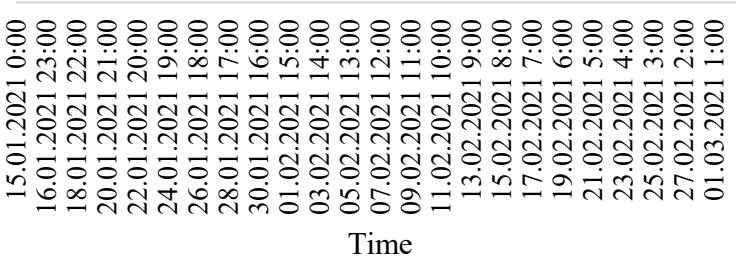

Fig. 8. Temperature variation in accumulation tank of solar collectors over time

\section{Conclusions}

Ground source HPS provides a constant heat consumption in a volume that is almost independent of outdoor temperature. However, the system efficiency is gradually decreasing due to the decreasing ground thermal potential.
Air HPS operates for about $8.2 \%$ of the heating period with a transformation coefficient close to 1 , but the rest of time the system is able to provide a heat consumption that will not decrease over time, unlike a ground source HPS.

The efficiency of solar collectors in winter is greatly reduced by low ambient temperatures, low sunlight hours, and frequent covering of the receiving surface with snow. However, solar collectors are able to supply hot water consumption during the inter-heating period and marginal months of heating period.

To improve the efficiency of renewable energy application for heat supply of stand-alone buildings under moderate continental climate conditions, typical for Moscow city, optimization of operation modes of heat supply sources, use of heat accumulation system, as well as maintaining the efficiency of HPS with geothermal circuit by recovering the ground thermal potential are required.

The investigation was carried out within the framework of the project "Efficiency improvement of combined building heating and cooling unit based on renewable energy sources" with the support of a grant from NRU "MPEI" for implementation of scientific research programs "Energy", "Electronics, Radio Engineering and IT", and "Industry 4.0, Technologies for Industry and Robotics in 2020-2022.

\section{References}

1. Order of the Ministry of Energy of Russia of 28.01.2019 N 45 " On approval of the action plan of the energy sector of the Russian Federation for the period 2019 - 2024 " / M: Russian Ministry of Energy, 2019. - $70 \mathrm{p}$.

2. " Forecast of scientific and technological development of the fuel and energy complex of Russia for the period up to 2035" (approved by the Minister of Energy of the Russian Federation on October 14, 2016) / M: Russian Ministry of Energy, 2016. - 106 p.

3. IEA. IEA (2019), Renewables 2019, IEA, Paris https://www.iea.org/reports/renewables-2019, 2019

4. IEA (2020), Heat Pumps, IEA, Paris https://www.iea.org/reports/heat-pumps, 2020.

5. L. Yang Heat pump market development in China, Heat Pumping Technologies, vol.38 №3/2020, 2020.

6. Z. Liu, D. Wu, H. Yu, W. Ma, G. Jin Field measurement and numerical simulation of combined solar heating operation modes for domestic buildings based on the Qinghai-Tibetan plateau case // Energy and Buildings, Vol. 167, 2018. pp. 312-321.

7. T. Long, Z. Qiao, M. Y. Wang, Li, J. Lu, W. Li, L. Zeng, S. Huang Performance analysis and optimization of a solar-air source heat pump heating system in Tibet, China // Energy and Buildings, Vol. 220, 2020. P. 110084

8. A. Georgiev, R. Popov, E. Toshkov Investigation of a hybrid system with ground source heat pump and solar collectors: Charging of thermal storages and space heating // Renewable Energy, Vol. 147, 2020. pp. 2774-2790. 
9. X. Wang, M. Zheng, W. Zhang, S. Zhang, T. Yang Experimental study of a solar-assisted ground-coupled heat pump system with solar seasonal thermal storage in severe cold areas // Energy and Buildings, Vol. 42, 2010. pp. 2104-2110.

10.Z. Dong, Q. Boyi, W. Chunlong Energy-saving evaluation and control optimization of an ASHP heating system based on indoor thermal comfort // Solar Energy, Vol. 194, 2019. pp. 913-922.

11. H. Averfalk, P. Ingvarsson, U. Persson, M. Gong, S. Werner Large heat pumps in Swedish district heating systems // Renewable and Sustainable Energy Reviews, Vol. 79, 2017. pp. 1275-1284.

12. M. Åberg, L. Fälting, D. Lingfors, A.M. Nilsson, A. Forssell Do ground source heat pumps challenge the dominant position of district heating in the Swedish heating market? // Journal of Cleaner Production, Vol. 254, 2020. P. 120070.

13. G. Fang, W. Chen, C. Wang, M.Y. Chan, S. Deng, X. Liu, H. Yan A novel air source heat pump powered bed-based space heating (ASHP-BBSH) system for improved indoor thermal environment // Energy Procedia, Vol. 158, 2019. pp. 2231-2236.

14. S. Maddah, M. Goodarzi, M.R. Safaei Comparative study of the performance of air and geothermal sources of heat pumps cycle operating with various refrigerants and vapor injection // Alexandria Engineering Journal, Vol. 59, 2020. pp. 4037-4047.

15. Q. Zhang, L. Zhang, J. Nie, Y. Li Techno-economic analysis of air source heat pump applied for space heating in northern China // Applied Energy, Vol. 207, 2017. pp. 533-542. 